Saudi Journal of Oral and Dental Research

Abbreviated Key Title: Saudi J Oral Dent Res

ISSN 2518-1300 (Print) |ISSN 2518-1297 (Online)

Scholars Middle East Publishers, Dubai, United Arab Emirates

Journal homepage: http://scholarsmepub.com/sjodr/

\title{
Assessment of Treatment Outcomes Using Centrographic Analysis of Skeletal Class II Malocclusion
}

\author{
Dr. Janani Jayapal, BDS ${ }^{1 *}$, Dr. Priyanka Venkatasubramanian, BDS $^{2}$, Dr. Sanjay Sundararajan, BDS, MDS ${ }^{3}$, Dr. Ratna \\ Parameswaran, BDS, $\mathrm{MDS}^{4}$, Dr. Devaki vijayalakshmi, BDS, $\mathrm{MDS}^{5}$ \\ ${ }^{1}$ Post graduate, Dept of Orthodontics and Dentofacial Orthopeadics Meenakshi Ammal Dental College, Tamil Nadu 600095, India \\ ${ }^{2}$ Postgraduate, Dept of Orthodontics and Dentofacial Orthopeadics, Meenakshi Ammal Dental College, Tamil Nadu 600095, India \\ ${ }^{3,4}$ Professor, Dept of Orthodontics and Dentofacial Orthopeadics, Meenakshi Ammal Dental College, Tamil Nadu 600095, India \\ ${ }^{5}$ Professor \& HOD, Dept of Orthodontics and Dentofacial Orthopeadics, Meenakshi Ammal Dental College, Tamil Nadu 600095, India
}

\begin{abstract}
DOI: $10.36348 /$ sjodr.2020.v05i01.004
| Received: 04.01.2020 | Accepted: 11.01.2020 | Published: 20.01.2020
\end{abstract}

*Corresponding author: Dr. Janani Jayapal

\section{Abstract}

\begin{abstract}
Aim: The main objective of the study is to assess and compare the skeletal and dental changes obtained before and after treatment using centrographic analysis in patients with class II skeletal base using three different treatment modalities Functional, Fixed Functional and Surgical (BSSO advancement). Materials and methods: A sample of 240 retrospectively collected pre-and post-treatment lateral cephalograms of class II malocclusion treated by orthodontics or orthodontic-surgical combined approach are included. The samples are grouped as Group I - Functional appliances (Twin Block appliance), Group II - Fixed functional appliances (AdvnSync II) and Group III - Surgical (BSSO advancement). The lateral cephalograms are traced and analysed using Centro-graphic analysis on FACAD 3.10 (Ilexis AB, Sweden). The post-treatment cephalograms are analysed to compare the treatment outcomes amongst the groups. Results: The results show high statistical significance in post-treatment class II skeletal correction among the three groups - also, a sharp reduction in the prognathic maxilla in the fixed functional group. The post-treatment mandibular prognathism was observed in the functional and surgical group. In terms of vertical component, the most significant neutral position of FC was found to be in the fixed functional group. Conclusion: This study primarily establishes a non-numerical method of evidence of highly significant mandibular changes were observed across the three groups. The most effectively treated subjects were found to be of the BSSO advancement group followed by functional and fixed functional groups, respectively.
\end{abstract}

Keywords: Non-numerical analysis, Centrographic analysis, Class II skeletal base, Functional, Fixed functional, bilateral sagittal split osteotomy.

Copyright @ 2020: This is an open-access article distributed under the terms of the Creative Commons Attribution license which permits unrestricted use, distribution, and reproduction in any medium for non-commercial use (NonCommercial, or CC-BY-NC) provided the original author and source are credited.

\section{INTRODUCTION}

Lateral cephalograms have been used by orthodontists for over 60 years to evaluate growth of the cranium and effects of treatment. Broadbent used the cephalometer, as it was called, to study growing children over time. He developed a method of superimposition of successive films whereby landmarks were identified and geometrically related. His sequential analysis of lateral radiographs was the first longitudinal perspective on cranial growth. Since then, many cephalometric analyses and their limitations have been described [1-4].

To establish reliability in cephalometric determinations, orthodontists have scrutinized the lateral anatomic representation by applying many analytical methods, including lines, angles, arcs, triangles, squares, and rectangles. Measurements often represent conflicting interpretations and do not rationally depict growth patterns known to exist. So, non-numerical analyses have been developed to avoid comparisons of patients with normative values $[5,6]$.

A cephalometric superimposition is an analysis of lateral cephalograms of the same patient taken at different times. These superimpositions are used to evaluate a patient's growth pattern between different ages and to evaluate changes in the dentoalveolar and basal relationships after a course of orthodontic or surgical treatment. However, if such superimpositions are to be meaningful, the appropriate procedures must be executed in a technically accurate and biologically sound manner [2]. 
The centroid analysis was first introduced by Johnson as a non-numerical method of assessing skeletal changes and it was later modified by Fishman in the year 1997. In the original centrographic analysis, Johnson described the use of the center of gravity as a fixed reference point. The centrographic analysis abates the time and effort and reduces the task to the construction of four centroids with common and simple methods of tracing and landmark identification, with no angles to measure and no normative values to compare [2].

The Centrographic analysis is unique to each patient; it supplies independent identification of anteroposterior positions of the maxilla and the mandible, vertical facial proportion inequalities, and a stable reference plane, which can be used for longitudinal cephalometric superimposition. Centroid being the center of a 3-dimensional object was chosen to be reliable in studies done with centrographic analysis. Four triangles are drawn which represents the upper face, lower face, total face and cranium. Much information can be obtained from the 4 triangles and their respective centroids. It aids in the evaluation of facial form graphically without the need for potentially invalid numerical standards of reference [1-4].

Previous studies on centrographic analysis have established a positive reliability and validity of this technique [3, 6, 7]. But no data is available comparing the pre and the post changes using centrographic analysis. Hence, the purpose of the present study is to evaluate the pretreatment and post treatment changes in patients with class II skeletal base who were treated with functional, fixed functional and surgical treatment modalities using centrographic analysis.

\section{MATERIAL \& METHODS}

This retrospective study was performed on a pre and post treatment selected sample of 120 lateral cephalometric radiographs of skeletal class II orthodontic patients (35males and 40females). The samples were grouped as Group I - treated by functional appliances, Group II - treated by fixed functional appliances and Group III - treated by surgical mandibular advancement using bilateral sagittal split osteotomy procedure with no age restrictions. This study was carried out from the Department of Orthodontics \& Dentofacial orthopaedics, Faculty of Dentistry, Meenakshi Ammal Dental College, Chennai.

The records included in this study followed the inclusion criteria of:

- A full complement of permanent teeth excluding the third molars.
- No significant medical history that would affect the growth and development of the bone and no history of trauma.

- No deformity in the nasomaxillary complex.

- No previous history of orthodontic treatment or maxillofacial surgery.

\section{CENTRO-GRAPHIC ANALYSIS}

The centroid analysis as described by Fishman was adopted [2]. This technique uses an adaptation of three triangles representing the face. For each triangle, the centroid was constructed by intersection of two or three planes derived by connecting a triangular vertex to the midpoint of the opposing side. This centroid illuminates the center of gravity or mass of this threedimensional object on a two-dimensional plane. The following three centroids are plotted on the lateral cephalograms

- $\quad$ Upper centroid (UC) for the upper face triangle. [(Ba- N- A) triangle]

- $\quad$ Lower centroid (LC) for the lower face triangle. [(Ba- A- Gn) triangle]

- Facial centroid (FC) for the total face triangle. [(Ba- N- Gn) triangle]

\section{Centro-graphic horizontal skeletal evaluation}

The horizontal assessment of maxillary and mandibular complexes is done using the centroids UC and LC and their relationship to FC.

- The UC is evaluated through its position - posterior or anterior to FC and recorded as maxillary retrognathism or prognathism.

- The LC is evaluated through its position - posterior or anterior to FC and recorded as mandibular retrognathism or prognathism.

\section{Centro-graphic vertical skeletal evaluation:}

The vertical position of FC to a line formed by $\mathrm{Ba}-\mathrm{A}$ plane gives the vertical harmony of the face.

- The location of FC directly on the Ba- A plane is regarded as neutral.

- The location of FC inferior to the Ba- A plane is regarded as a Long face.

- The location of FC superior to the Ba- A plane is regarded as a Short face.

The following evaluations was analysed on pre and post treatment lateral cephalograms and compared to assess the treatment outcomes amongst the three groups using the FACAD 3.10 (Ilexis AB, Sweden) digital orthodontic tracing software.

\section{Reliability}

All cephalometric radiographs used in this study were traced and analyzed by the same operator and checked by the supervisors. To minimize the errors, landmark identification was rechecked by the same 
operator. To assess the intra-examiner reliability, 20 cephalometric radiographs were randomly selected, retraced and reanalyzed after 8 weeks after the first measurement. A paired sample t- test was applied to the first and second measurements. It was found that the difference between the first and second measurements of the 20 radiographs was insignificant.

\section{STATISTICAL ANALYSIS}

The collected data were analyzed using the IBM SPSS version 19.0 (IBM Crop.) with Chi-square test to compare the differences between pre- and posttreatment outcomes of centrographic analysis. Null hypothesis was no difference between pre- and posttreatment outcomes amongst each group. The statistically significant level was set at $\mathrm{p}<0.05$.

\section{RESULTS}

The results as per centrographic analysis of pre and post skeletal class II orthodontic patients are tabulated (Table.1-6). The class II skeletal correction was a key feature seen from the results of the study (95\%). Comparing the pre and the post treatment groups, there exists a statistically significant reduction in maxillary prognathism post-treatment in fixed functional subjects $(12.5 \%)$ (p-0.052).

The mandibular component was assessed using the lower centroid (LC) in relation to facial centroid (FC). The anterior position of LC to FC indicating the prognathic mandible is not evident in all three groups. In functional appliances and BSSO advancement group (5\%) the mandible showed more forward positioning than the fixed functional group, post treatment. The mandible in all the three groups has shown highly statistically significant changes in post-treatment outcomes compared to pre-treatment. The BSSO advancement group (p-0.001) showed the most advancement followed by functional appliances group (p-0.021) and then fixed functional appliances group ( $\mathrm{p}$ $0.041)$.

The evaluation of vertical discrepancies through the position of $\mathrm{FC}$ in relation to Ba-A plane by chi-square test, points out an overall statistical increase in neutral position of FC in all three groups. The fixed functional group have shown to achieve a statistically significant change to neutral position of FC $(56.5 \%)$ (p$0.001)$

Table-1: Pre-treatment relationship between anteroposterior positions of UC to FC

\begin{tabular}{|c|c|c|c|c|}
\hline \multirow{2}{*}{ PRE-TREATMENT } & \multicolumn{2}{|c|}{ MAXILLARY RETROGNATHIC } & \multicolumn{2}{c|}{ MAXILLARY PROGNATHIC } \\
\cline { 2 - 5 } & $\begin{array}{c}\text { YES } \\
\mathbf{n}(\boldsymbol{\%})\end{array}$ & $\begin{array}{c}\text { NO } \\
\mathbf{n}(\boldsymbol{\%})\end{array}$ & $\begin{array}{c}\text { YES } \\
\mathbf{n}(\boldsymbol{\%})\end{array}$ & $\begin{array}{c}\text { NO } \\
\mathbf{n}(\boldsymbol{\%})\end{array}$ \\
\hline $\begin{array}{c}\text { FUNCTIONAL } \\
\text { APPLIANCE } \\
\text { (TWIN BLOCK) }\end{array}$ & $3(7.5)$ & $37(92.5)$ & $17(45.94)$ & $23(54.05)$ \\
\hline $\begin{array}{c}\text { FIXED FUNCTIONAL } \\
\text { (AdvnSync II) }\end{array}$ & $1(2.5)$ & $39(97.5)$ & $11(28.20)$ & $29(71.79)$ \\
\hline BSSO Advancement & 0 & $40(100)$ & $7(17.5)$ & $33(82.5)$ \\
\hline
\end{tabular}

Table-2: Pre-treatment relationship between anteroposterior positions of LC to FC

\begin{tabular}{|c|c|c|c|c|}
\hline \multirow{2}{*}{ PRE-TREATMENT } & \multicolumn{2}{|c|}{ MANDIBULAR RETROGNATHIC } & \multicolumn{2}{c|}{ MANDIBULAR PROGNATHIC } \\
\cline { 2 - 5 } & $\begin{array}{c}\text { YES } \\
\mathbf{n}(\boldsymbol{\%})\end{array}$ & $\begin{array}{c}\text { NO } \\
\mathbf{n}(\boldsymbol{\%})\end{array}$ & $\begin{array}{c}\text { YES } \\
\mathbf{n}(\boldsymbol{\%})\end{array}$ & $\begin{array}{c}\text { NO } \\
\mathbf{n}(\boldsymbol{\%})\end{array}$ \\
\hline $\begin{array}{c}\text { FUNCTIONAL } \\
\text { APPLIANCE } \\
\text { (TWIN BLOCK) }\end{array}$ & $38(95)$ & $2(5)$ & 0 & $40(100)$ \\
\hline $\begin{array}{c}\text { FIXED FUNCTIONAL } \\
\text { (AdvnSync II) }\end{array}$ & $37(92.5)$ & $3(3.75)$ & 0 & $40(100)$ \\
\hline $\begin{array}{c}\text { BSSO } \\
\text { Advancement }\end{array}$ & $40(100)$ & 0 & 0 & $40(100)$ \\
\hline
\end{tabular}

Table-3: Pre-Treatment relationship between vertical positions of FC

\begin{tabular}{|c|c|c|c|}
\hline PRE-TREATMENT & $\begin{array}{c}\text { INFERIOR } \\
\mathbf{n}(\boldsymbol{\%})\end{array}$ & $\begin{array}{c}\text { SUPERIOR } \\
\mathbf{n}(\boldsymbol{\%})\end{array}$ & $\begin{array}{c}\text { NEUTRAL } \\
\mathbf{n}(\boldsymbol{\%})\end{array}$ \\
\hline $\begin{array}{c}\text { FUNCTIONAL } \\
\text { APPLIANCE } \\
\text { (TWIN BLOCK) }\end{array}$ & $8(20)$ & $19(47.5)$ & $13(32.5)$ \\
\hline $\begin{array}{c}\text { FIXED FUNCTIONAL } \\
\text { (AdvnSync II) }\end{array}$ & $3(8.10)$ & $27(72.97)$ & $10(27.07)$ \\
\hline $\begin{array}{c}\text { BSSO } \\
\text { Advancement }\end{array}$ & $16(40)$ & $21(52.5)$ & $3(7.5)$ \\
\hline
\end{tabular}


Table-4: Post-treatment relationship between anteroposterior positions of UC to FC

\begin{tabular}{|c|c|c|c|c|}
\hline POST-TREATMENT & \multicolumn{2}{|c|}{ MAXILLARY RETROGNATHIC } & \multicolumn{2}{c|}{ MAXILLARY PROGNATHIC } \\
\cline { 2 - 5 } & $\begin{array}{c}\text { YES } \\
\mathbf{n}(\boldsymbol{\%})\end{array}$ & $\begin{array}{c}\text { NO } \\
\mathbf{n}(\boldsymbol{\%})\end{array}$ & $\begin{array}{c}\text { YES } \\
\mathbf{n}(\boldsymbol{\%})\end{array}$ & $\begin{array}{c}\text { NO } \\
\mathbf{n}(\boldsymbol{\%})\end{array}$ \\
\hline $\begin{array}{c}\text { FUNCTIONAL } \\
\text { APPLIANCE } \\
\text { (TWIN BLOCK) }\end{array}$ & $3(7.5)$ & $37(92.5)$ & $14(37.83)$ & $26(62.16)$ \\
\hline $\begin{array}{c}\text { FIXED FUNCTIONAL } \\
\text { (AdvnSync II) }\end{array}$ & $5(12.5)$ & $35(87.5)$ & $6(12.82)$ & $34(87.17)$ \\
\hline $\begin{array}{c}\text { BSSO } \\
\text { Advancement }\end{array}$ & 0 & $40(100)$ & $7(17.5)$ & $33(82.5)$ \\
\hline
\end{tabular}

Table-5: Post-treatment relationship between anteroposterior positions of $\mathrm{LC}$ to $\mathrm{FC}$

\begin{tabular}{|c|c|c|c|c|}
\hline \multirow{2}{*}{ POST-TREATMENT } & \multicolumn{2}{|c|}{ MANDIBULAR RETROGNATHIC } & \multicolumn{2}{c|}{ MANDIBULAR PROGNATHIC } \\
\cline { 2 - 5 } & $\begin{array}{c}\text { YES } \\
\mathbf{n}(\boldsymbol{\%})\end{array}$ & $\begin{array}{c}\text { NO } \\
\mathbf{n}(\boldsymbol{\%})\end{array}$ & $\begin{array}{c}\text { YES } \\
\mathbf{n}(\boldsymbol{\%})\end{array}$ & $\begin{array}{c}\text { NO } \\
\mathbf{n}(\boldsymbol{\%})\end{array}$ \\
\hline $\begin{array}{c}\text { FUNCTIONAL } \\
\text { APPLIANCE } \\
\text { (TWIN BLOCK) }\end{array}$ & $5(12.5)$ & $35(87.5)$ & $2(5)$ & $38(95)$ \\
\hline $\begin{array}{c}\text { FIXED FUNCTIONAL } \\
\text { (AdvnSync II) }\end{array}$ & $14(35)$ & $26(65)$ & 0 & $40(100)$ \\
\hline $\begin{array}{c}\text { BSSO } \\
\text { Advancement }\end{array}$ & $7(17.5)$ & $33(82.5)$ & $2(5)$ & $38(95)$ \\
\hline
\end{tabular}

Table-6: Post-Treatment relationship between vertical positions of FC

\begin{tabular}{|c|c|c|c|}
\hline $\begin{array}{c}\text { POST- } \\
\text { TREATMENT }\end{array}$ & $\begin{array}{c}\text { INFERIOR } \\
\mathbf{n}(\boldsymbol{\%})\end{array}$ & $\begin{array}{c}\text { SUPERIOR } \\
\mathbf{n}(\boldsymbol{\%})\end{array}$ & $\begin{array}{c}\text { NEUTRAL } \\
\mathbf{n}(\boldsymbol{\%})\end{array}$ \\
\hline $\begin{array}{c}\text { FUNCTIONAL } \\
\text { APPLIANCE } \\
\text { (TWIN BLOCK) }\end{array}$ & $11(27.5)$ & $6(15)$ & $23(57.5)$ \\
\hline $\begin{array}{c}\text { FIXED } \\
\text { FUNCTIONAL } \\
\text { (AdvnSync II) }\end{array}$ & $1(2.5)$ & $13(32.5)$ & $26(56.5)$ \\
\hline $\begin{array}{c}\text { BSSO } \\
\text { Advancement }\end{array}$ & $18(45)$ & $5(12.5)$ & $17(42.5)$ \\
\hline
\end{tabular}

\section{DISCUSSION}

The centrographic analysis employs a point called centroid which forms the two dimensional geometrically derived representation of the center of mass of a three-dimensional object such as a patient's skeletal pattern [1]. This study adopts a method of centrographic analysis put forth by Fishman which lays down a matrix of four triangles representing the maxilla, mandible, total face, and cranium derived from anatomic skeletal landmarks [2]. This method provides clinicians with simplified tracing techniques to assess the maxillomandibular relationship. The centroid derived in this study was found to be the most reliable point compared to various other cephalometric landmarks. And the human faces are regarded as most pleasant when the upper, lower and the facial centroids fall on the same vertical plane [3].

To the best of our knowledge, this study is the first attempt of utilizing cento-graphic analysis to assess the outcomes of an orthodontic treatment using all the three modalities in Class II skeletal treatment functional, fixed functional and surgical. Previous research involving the centrographic analysis was usually restricted to assessing the reliability of centroid and the evaluation of morphological features [4-7].

The past research even includes the complex incorporation of numerical methods along with centrographic analysis which is predominantly nonnumerical to identify effects on the timing of orthodontic treatment. This study utilizes the nonnumerical method to evaluate skeletal facial balance from 240 pre-and post-treatment lateral cephalograms of skeletal class II malocclusion, treated by functional, fixed functional and BSSO advancement subjects. Also, this study aids to assess and compare the outcomes of skeletal facial balances of these patients in depth.

The results of this study shows a predominant feature in relation to the maxillary position evaluated using UC relation to $\mathrm{FC}$, The maxillary position is prodominatly protrusive rather very rarely retrusive in skeletal class II which agrees with the results of past researchers[8, 9]. The results of mandibular position evaluated by $\mathrm{LC}$ to $\mathrm{FC}$ are in records with the past 
Janani Jayapal et al; Saudi J Oral Dent Res, Jan 2020; 5(1): 24-29

studies indicating a mandibular retrusion being the most common feature to skeletal class II malocclusion [10,11].

The comparison to pre and post-treatment results of the functional appliance group in this study are in agreement with many previous studies which have reported significant mandibular retrusion correction with twin block appliance. However, there is a significant reduction in superior position of FC in this study which was differing from the results of the study by Mills in 1998[12-14].

The results in this study evaluating the anteroposterior position of UC in relation to FC in fixed functional group, has a oneness with the results of study by Jayachandran et al. 2016, there exists an increase in the posterior movement of UC in regards with fixed functional appliance compared with other groups. However, there in reduction in anterior movement of LC in Fixed function group compared with other subject groups $[15,16]$.

The study results evaluating the surgical treatment approach involving BSSO advancement in skeletal class II malocclusion shows movement of LC anteriorly and reduced shortening of face which is in concordance with the study done by Strom in 2011. Also, when compared to the other groups, the BSSO advancement shows higher anterior LC movement which is also similar to the results from the study by Colin in 2003. The overall inter-group comparison shows better treatment results with surgical approach as compared with functional and fixed functional appliances [17-19].

This retrospective study using the centroid analysis provides a key non-numerical platform to compare and assess both orthodontic and orthodonticsurgical treatment approaches in skeletal class II malocclusion. The outcomes of this study evaluating and comparing the pre-and post-treatment outcomes of functional, fixed functional appliances, and surgical intervention on skeletal class II malocclusion provides an add on reliability comparison with previously reported data. Also, our results open up a far bigger controversy relating better treatment results being achieved with orthodontic-surgical approach as compared with orthodontic approach only in correcting skeletal class II malocclusion.

\section{CONCLUSION}

Post treatment sagittal parameters indicates that

- Maxilla was less prognathic in case of fixed functional group followed by functional and BSSO advancement groups.

- Mandibular advancement was more pronounced in BSSO advancement group followed by functional group and fixed functional groups.
Post treatment vertical parameters indicates that

- Shortening of maxilla was evident in fixed functional group compared to functional and BSSO advancement groups.

- Increase in lower third was prominent in BSSO advancement group than functional and fixed functional groups.

\section{REFERENCES}

1. Johnson, J.S., Hubbold, R.J. (1982). An introduction to centroid cephalometrics. British Journal of Orthodontics, 9(1), 32-6.

2. Fishman, L.S. (1997). Individualized evaluation of facial form. Am J Orthod Dentofacial Orthop, 111(5), 510-7.

3. Johnson, J.S. (1960). The use of centres of gravity in cephalometric analysis. Dent Pract, 10, 107-13.

4. Lakshmipulagam, Parameswaran, R. (2017). Reliability and accuracy of Centrographic analysis in comparisonwith other superimposition techniques - A Cephalometric study. IOSR Journal of Dental and Medical Sciences, 16(10), 81-86.

5. Basciftci, F.A., Uysal, T., Buyukerkmen, A. (2004). Craniofacial structure of Anatolian Turkish adults with normal occlusions and wellbalanced faces. Am J Orthod Dentofacial Orthop, 125(3),366-372.

6. Munish, C.R., Gupta, S. (2015). The applicability of centrographic analysis in pleasing craniofacial phenotypes. APOS Trends in Orthodontics, 5(4), 144-150.

7. Dolce, C., Schader, RE., McGorray, S.P., Wheeler, T.T. (2005). Centrographic analysis of 1-phase versus 2-phase treatment for Class II malocclusion. Am J Orthod Dentofacial Orthop, 128(2), 195-200.

8. Rosenblum, R.E. (1995). Class II malocclusion: mandibular retrusion or maxillary protrusion? Angle Orthod, 65(1), 49-62.

9. Baccetti, T., Franchi, L., McNamara, J.A Jr., Tollaro, I. (1997). Early dentofacial features of Class II malocclusion: a longitudinal study from the deciduous through the mixed dentition. Am J Orthod Dentofacial Orthop, 111(5), 502-9.

10. Emad, A. A. A., Susan, N.A. (2009). Anteroposterior and Vertical Components of Class II division 1 and division 2 Malocclusion. The Angle Orthodontist, 79(5), 859-866.

11. Moyers, R.E., Riolo, M.L., Guire, K.L., Wainright, R.L. (1980). Differential diagnosis of Class II malocclusions Part 1. Facial types associated with Class II malocclusions. Am J Orthod, 78(5), 47794.

12. Mills, C.M., McCulloch, K.J. (1998). Treatment effects of the twin block appliance: A cephalometric study. Am J Orthod Dentofacial Orthop, 114(1), 15-24.

13. Lund, D.I., Sandler, P.J. (1998). The effects of twin blocks: A prospective controlled study. Am J Orthod Dentofacial Orthop, 113(1), 104-10. 
14. Toth, L.R., McNamara, J.J. (1999). Treatment effects produced by the twin- block appliance and the FR-2 appliance of Frankel compared with an untreated Class II sample. Am J Orthod Dentofacial Orthop, 116(6), 597-609.

15. Jayachandrana, S., Wiltshireb, A.W., Hayasakic, S.M., Pinheiro, F.H.S.L. (2016). Comparison of AdvanSync and intermaxillary elastics in the correction of Class II malocclusions: A retrospective clinical study. Am $J$ Orthod Dentofacial Orthop, 150(6), 979-988.

16. Koretsi, V., Papageorgiou, S.N., Papadopoulos, M.A. (2016).Treatment effects of fixed functional appliances in patients with Class II malocclusion: a systematic review and meta-analysis. European Journal of Orthodontics, 38(2),113-126.

17. Storms, A.S., Miclotte, A., Grosjean, L., LlanoPérula, M.C., Alqerban, A., Fieuws, Sun, S.Y.,
Politis, C., Verdonck, A., Willems, G. (2017). Short-term hard and soft tissue changes after mandibular advancement surgery in Class II patients: a retrospective cephalometric study. European Journal of Orthodontics, 39(5), 567-576.

18. Colin, A., Proffit, W.R., Phillips, C. (2003). Longterm follow-up of Class II adults treated with orthodontic camouflage: A comparison with orthognathic surgery outcomes. American Journal of Orthodontics and Dentofacial Orthopedics, 123(3), 266-78.

19. Kabbur, K.J., Hemanth, M., Patil, G.S., Sathyadeep, V., Shamnur, N., Harieesha, K.B., Praveen, G.R. (2012). An esthetic treatment outcome of orthognathic surgery and dentofacial orthopedics in class II treatment: a cephalometric study. J Contemp Dent Pract, 13(5), 602-6. 